\title{
MODELS OF INDIVIDUAL LINEAR DIMENSIONS NECESSARY FOR THE CONSTRUCTION OF THE CORRECT FORM OF DENTAL ARCHES IN YOUNG MEN WITH A WIDE FACE, DEPENDING ON THE FEATURES OF ODONTOMETRIC AND CEPHALOMETRIC INDICATORS
}

DOI: 10.36740/WLek202006104

\author{
Alla V. Marchenko', Mariya M. Shinkaruk-Dykovytska' ${ }^{2}$, Taras P. Pozur' ${ }^{2}$, Valery I. Gunas ${ }^{2}$, Volodymyr O. Orlovskiy ${ }^{2}$ \\ 'UKRAINIAN MEDICAL STOMATOLOGICAL ACADEMY, POLTAVA, UKRAINE \\ 2NATIONAL PIROGOV MEMORIAL MEDICAL UNIVERSITY, VINNYTSIA, UKRAINE
}

\begin{abstract}
The aim is development and analysis of regression models of linear dimensions necessary for the construction of the correct form of dental arches in young men with a wide face, depending on the features of odontometric and cephalometric indicators.

Material and methods: Primary computed tomographic indices of tooth size and cephalometric parameters of 44 young men with normal occlusion were obtained from the data bank of the National Pirogov Memorial Medical University, Vinnytsya. Face type was determined using the Garson morphological index. In licensed statistical package "Statistica 6,0" developed regression models of linear dimensions necessary for the construction of the correct form of dental arches.

Results: As a result of researches, it is established that all 18 reliable models of the sizes used for construction of the correct form of dental arches, depending on peculiarities of odontometric and cephalometric indices with a coefficient from 0.645 to 0.944 are constructed. Built models in adolescents with a broad face type more often include odontometric than cephalometric indicators. The most commonly used odontometric indices are: the width of the crowns of the teeth in the mesio-distal and vestibulo-oral directions, as well as the distance from the middle of the cutting edge to the apex of the root of the teeth in the vestibulo-oral direction.

Conclusions: In adolescents with a broad type of face with normal occlusion, all 18 possible reliable regression models of reproduction of the individual characteristics of the dental arches of the upper and lower jaws were determined and analyzed.
\end{abstract}

KEY WORDS: young men with orthognathic bite, face type, odontometric and cephalometric parameters, regression analysis, dental arch

Wiad Lek. 2020;73(6):1103-1107

\section{INTRODUCTION}

A correct and bright smile has become a kind of "business card" of a person, and thus symbolizes his position in public life. That is why achieving such a result - an excellent "business card" has become the main goal of dentistry in recent decades.

Building a dentition is a complex process that requires a comprehensive approach. To get a harmonious smile, the doctor cannot act in a formulaic fashion. It should be based on the features of the patient's face, considering anthropometric points, and features of the teeth, considering odontometric parameters.

The fact of the relationship of the cranial skull with the parameters of the upper and lower jaws is proved. Differences of transversal sizes of lower and upper jaws in girls and boys with different head shapes revealed [1]. Specifics were also found in such odontometric parameters as the root length of the incisors and canines on the upper and lower jaws. Higher values of the investigated parameters were found in the representatives of mesocephals compared to brachycephals [2]. Face types affect the ratio of dental arches of the upper and lower jaws [3].
Equally important is the ethnic and regional component. Bedoya A. et al found significant differences in the bite force, dental arch transversal width, and bizygomatic width scores from representatives of three different tribes living in the Amazon. [4]. In this regard, there is a need to conduct research on individual populations, considering ethnicity. Such works are actively appearing in different corners of the world, which testifies to the significant relevance of this topic $[5,6]$. Of particular note is the work on the study of the relationship between the type of dental arches and face for different types of occlusion $[7,8]$.

Only the inclusion of the maximum number of variables (the maximum number of anthropometric points and lines on the brain and facial part of the skull; the maximum number of odontometric indicators) can ensure the completeness and integrity of the study [9].

\section{THE AIM}

The aim - development and analysis of regression models of linear dimensions necessary for the construction of the 
correct form of dental arches in young men with a wide face, depending on the features of odontometric and cephalometric indicators.

\section{MATERIAL AND METHODS}

Primary computed tomographic indices of tooth size and cephalometric parameters of 44 young men and 50 young women with normal occlusion close to orthognathic occlusion (determined by 11 points by MG Bushan et al. [10]) obtained from the data bank of the research center of $\mathrm{Na}$ tional Pirogov Memorial Medical University, Vinnytsya. All surveys of young men and young women were conducted on the informed consent principle. Bioethics Committee of National Pirogov Memorial Medical University, Vinnytsya (Protocol No. 3 of March 16, 2017) found that the studies carried out comply with the bioethical and moral requirements of the Declaration of Helsinki, the Council of Europe Convention on Human Rights and Biomedicine (1977), the relevant provisions of $\mathrm{WHO}$ and the laws of Ukraine under the order of the Ministry of Health of Ukraine No. 281 of 11.01 .2000 .

Dental cone-ray tomograph - Veraviewepocs 3D, Morita (Japan) was used for the study. The studies were conducted according to the scheme developed by Gunas I.V., Dmitriev N.A. and Marchenko A.V. [11] within the following characteristics: three-dimensional image volume $-8 \times 8 \mathrm{~cm}$ cylinder, $0.2 / 0.125 \mathrm{~mm}$ layer thickness, $11-48 \mu \mathrm{Sv}$ irradiation dose, $60-90 \mathrm{kV} / 2-10 \mathrm{~mA}$ voltage and current.

Metric indices of central (medial) and lateral (lateral) incisors, canines, first and second premolars, as well as the first molars of the upper and lower jaws were studied. Since in the previously conducted by Gunas I.V., Dmitriev N.A. and Marchenko A.V. studies [11] did not establish significant or trending differences when comparing CT-tomography sizes of the same teeth of the right and left sides, we further use the average values of the corresponding teeth on the upper and lower jaws: upper (11) or lower (41) central incisors; upper (12) or lower (42) lateral incisors; upper (13) or lower (43) canines; upper (14) or lower (44) first premolars; upper (15) or lower (45) second premolars; upper (16) or lower (46) first molars.

Measurement of the width of the crowns of the teeth (VSHIR, mm) and the width of the teeth at the level of the anatomic neck (MDDEG, $\mathrm{mm}$ ) in the mesio-distal direction; width of tooth crowns (TSHIR, $\mathrm{mm}$ ), width of teeth at the level of anatomic neck (VDEG, mm), distance from anatomical neck to apex of root (VLROOT, mm) and distance from middle of cutting edge to apex of root $(\mathrm{L}, \mathrm{mm})$ in vestibulo-oral (vestibulo-lingual) direction; as well as root and incisor root lengths (ALROOT, $\mathrm{mm}$ ) in the mesio-distal direction were performed in the i-Dixel One Volume Viewer [Ver.1.5.0] J Morita Mfg. Cor.

The following cephalometric dimensions were also measured (using a soft centimeter tape and Martin's compass, $\mathrm{mm}$ ) [12]: AL_AL is the width of the base of the nose (distance between the alar points); AU_AU - ear diameter (biauricular width); AU_GL is the distance from the auricular point to the glabella (averaged); AU_GN distance from auricular point to chin (average); AU_GO is the distance from the auricular point to the angle of the mandible (average); AU_N is the distance from the auricular point to the nasion (averaged); AU_SN - distance from auricular point to subnasion (averaged); AU-I is the distance from the auricular point to the interincisors point (averaged); CHI_CHI is the width of the mouth slit; DUG_AU_AU is a transverse arc measured by a ribbon from the right tragus point to the left; DUGS_G_OP is a sagittal arch measured by a ribbon from a glabella to the occipital point; DUG_G_OP - the largest girth of the head due to the glabella and nasion; EK_EK - exterior (biorbital) width (direct size between the outer corners of the eye slits); EU_EU - maximum head width (occipital diameter); FMT_FMT - smallest width of head (frontal diameter); G_OP - the greatest length of the head, is the distance from the glabella to the opisthocranion; GO_GN - mandibular body length (average); GO_GO - width of mandible (width between corners of mandible); LS_LI - height of red lip border; MF_MF is the inter-orbital (anterior inter-orbital) width (straight distance between the inner corners of the eye pits); N_GN - morphological length of the face (direct distance from the nasion to the gnathion); N_I is the distance between the nasion and the interincision point; N_PR - distance between nasion and prosthion; N_PRN - length of nose (distance between nasion and pronasion); N_SN - the height of the nose (distance between the supra-nasal and sub-nasal points); N_STO - the height of the upper part of the face (distance from the nasal to the oral points); SN_PRN - depth of nose (distance between sub-nasal point and pronaiion); SN_STO - height of upper lip (distance from sub-nasal point to sthomion); STO_GN - height of lower part of face (distance from mouth to chin point); STO_SPM - height of lower lip (distance from sthomion to supramental); TR_GN - physiological length of face (distance from trichion to gnathion); TR_N - forehead height (straight distance between trichion points (hairline) and nasion); V_GOL - the projection distance from the crown of the head (vertex) to the upper edge of the ear hole; ZM_ZM - average width of face (distance between zygomaxillary (zygomatic maxillary) points); ZY_ZY - width of face (distance between zygomatic points).

The type of face was determined using the Garson morphological index - the ratio of the morphological length of the face (the direct distance from the nasion to the gnathion) to the width of the face in the area of zygomatic arches [13]. With a value of up to 78.9 young men were referred to a group with a very wide face; 79.0-83.9 - wide face; 84.0-87.9 - average face; 88.0-92.9 - narrow face; 93.0 and above - very narrow face. The following distribution was established: with a very wide face -6 , with a wide face -25 , with an average face -6 , with a narrow face -6 , with a very narrow face -1 . Therefore, only young men with a wide face were selected for modeling.

In licensed statistical package "Statistica 6,0", using direct stepwise regression analysis, constructed mathematical models of the following characteristics of dental arches $(\mathrm{mm})$, 
depending on the features of odontometric and cephalometric indices: distances between the apexes of the palatine roots of the upper first molars (NAPX_16), between the apexes of the distal buccal roots of the upper first molars (DAPX_16), between the apexes of the medial buccal (vestibular) roots of the upper first molars (MAPX_16), between the apexes of the medial roots of the lower first molars (MAPX_46), between the apexes of the distal roots of the lower first molars (DAPX_46), between the molar points by Pon (PONM), between the premolar points by Pon (PONPR), between the vestibular medial cusp of the upper first molars (VESTBUGM), and between the cusp of the upper canine (BUGR13_23), between the apexes of the roots of the upper canine (APX13_23), between the cusp of the lower canine (BUGR33_43), between the apexes of the roots of the lower canine (APX33_43); as well as canine sagittal distance of the maxillary dental arch (DL_C), premolar sagittal distance of the maxillary dental arch (DL_F), molar sagittal distance of the maxillary dental arch (DL_S), depth of palate at the level of canine (GL_1) (GL_2) and palate depths at the level of the first molars (GL_3).

The following conditions were considered in the regression analysis: the final variant of the obtained equation must have a coefficient of determination $\left(\mathrm{R}^{2}\right)$ of at least 0.60 ; an F-criterion value of at least 3.0; the number of free members should be as low as possible. Residue analysis was also performed: when the obtained results fell within \pm 3 standard deviations from the mean, re-analysis with and without emissions was performed to ensure that they did not have any effect on the displacement of the final results [14].

\section{RESULTS}

In adolescents with a wide face type, regression models of linear dimensions necessary to construct the correct form of dental arches, depending on the odontometric and cephalometric indicators have the following linear equations:

NAPX_16 $=-0,316+5,930 \times$ MDDEG_42 + 3,670 $\times$ VSHIR_12 - 3,402 $\times$ TSHIR_15 $+0,069 \times$ DUGS_G_OP $0,639 \times \mathrm{L} \_41+1,308 \times \mathrm{TSHIR} \_44\left(\mathrm{R}^{2}=0,845 ; \mathrm{F}_{(6,18)}=16,34\right.$; $\mathrm{p}<0,001)$;

DAPX_16 $=64,63+3,723 \times$ VSHIR_45 $+3,244 \times$ TSHIR_13 - 0,424 $\times$ GO_GO $-1,601 \times$ L_42 + 1,111 $\times$ L_14 + 0,752 $\times$ VLROOT_43 - 0,588 $\times$ SN_PRN $\left(\mathrm{R}^{2}=0,883\right.$; $\left.\mathrm{F}_{(7,17)}=18,33 ; \mathrm{p}<0,001\right)$;

MAPX_16 $=15,33+2,206 \times$ VSHIR_45 $+5,748 \times$ TSHIR_41 $+0,943 \times$ SN_STO $-0,285 \times$ G_OP $+0,699$ $\times$ SN_PRN $+0,102 \times$ TR_N $\left(\mathrm{R}^{2}=0,900 ; \overline{\mathrm{F}}_{(6,18)}=27,14\right.$; $\mathrm{p}<0,001$ );

MAPX_46 $=15,90+2,250 \times$ TSHIR_16 $+1,497 \times$ L_43 - 3,870 $\times$ MDDEG_41 - 0,290 $\times$ N_SN $-1,265 \times$ VLROOT_11 + 2,428 $\times$ VSHIR_13 $\left(\mathrm{R}^{2}=0,936 ; \mathrm{F}_{(6,17)}=41,54\right.$; $\mathrm{p}<0,001)$;

DAPX_46 $=-0,170+0,326 \times$ SN_STO $+4,992 \times$ VSHIR_14 - 3,805 $\times$ VDEG_42 + 1,886 $\times$ MDDEG_12 $+1,511 \times$ TSHIR_16 $-1,359 \times$ TSHIR_14 $\left(\mathrm{R}^{2}=0,793\right.$; $\left.\mathrm{F}_{(7,16)}=8,73 ; \mathrm{p}<0,001\right)$;
$P O N M=6,372+1,373 \times$ TSHIR_15 $+0,205 \times$ AU_GN $+2,825 \times$ VDEG_43 - 0,367 $\times$ N_SN $-2,155 \times$ VDEG_42 $+2,490 \times$ VSHIR_44 $-0,520 \times$ TSHIR_14 $\left(\mathrm{R}^{2}=0,893\right.$; $\left.\mathrm{F}_{(7,17)}=20,34 ; \mathrm{p}<0,001\right)$;

VESTBUGM $=-6,515+1,213 \times$ TSHIR_ $15+0,313 \times$ AU_GN + 2,441 $\times$ VSHIR_43 - 0,234 $\times$ N_SN + 0,685 $\times$ $\mathrm{L} \_44-0,388 \times \mathrm{L} \_13\left(\mathrm{R}^{2}=0,914 ; \mathrm{F}_{(6,18)}=31,76 ; \mathrm{p}<0,001\right)$;

PONPR $=-8,931+1,404 \times$ VSHIR_43 $+1,116 \times$ VSHIR_16 + 0,077 $\times$ ZM_ZM + 0,982 $\times$ VSHIR_12 + $1,401 \times$ TSHIR_11 - 0,261 $\times$ VLROOT_41 + 0,178 $\times$ L_12 $\left(\mathrm{R}^{2}=0,942 ; \mathrm{F}_{(7,17)}=39,31 ; \mathrm{p}<0,001\right)$;

BUGR13_23 $=-59,91+3,618 \times$ VSHIR_11 $+0,107 \times$ DUG_G_OP + 2,863 $\times$ VDEG_43 + 0,960 × ALROOT_42 $-0,328 \times \mathrm{L} \_42-0,268 \times \mathrm{N} \_$STO $-1,116 \times$ MDDEG_11 $\left(\mathrm{R}^{2}=0,904 ; \overline{\mathrm{F}}_{(7,17)}=22,82 ; \mathrm{p}<0,001\right)$;

APX13_23 $=57,98+0,686 \times \mathrm{L} \_14+1,562 \times$ MDDEG_12 $-3,119 \times$ VSHIR_43 - 0,418 $\times$ VLROOT_41 - 0,155 $\times$ TR_N $+0,495 \times$ LS_LI $-0,151 \times$ V_GOL $\left(R^{2}=0,875\right.$; $\left.\mathrm{F}_{(7,16)}=16,04 ; \mathrm{p}<0,001\right)$;

BUGR33_43 $=8,675+2,529 \times$ VSHIR_12 $+0,724 \times$ L_44 - 0,619 $\times$ ALROOT_11 - 1,921 $\times$ MDDEG_12 + $2,243 \times$ VDEG_42 - 0,311 $\times$ L_14 $\left(\mathrm{R}^{2}=0,944 ; \mathrm{F}_{(7,17)}=41,25\right.$; $\mathrm{p}<0,001)$;

APX33_43 = 6,277 + 0,177 $\times$ AU_GO - 0,603 $\times$ STO $\mathrm{SPM}+1,115 \times$ VSHIR_43 $-1,359 \times$ VLROOT_11 $+0,812 \times$ L_43 + 1,493 $\times$ VSHIR_12 $\left(\mathrm{R}^{2}=0,768 ; \mathrm{F}_{(6,18)}=9,91 ; \mathrm{p}<0,001\right)$;

DL_C $=-26,14+1,775 \times$ VSHIR_11 $+0,103 \times$ EU_EU $+1,160 \times$ MDDEG_42 $\left(\mathrm{R}^{2}=0,645 ; \overline{\mathrm{F}}_{(3,21)}=12,72 ; \mathrm{p}<0,001\right)$;

$\boldsymbol{D} \boldsymbol{L} \_\boldsymbol{F}=-10,64+2,038 \times$ VSHIR_11+0,682 $\times$ VSHIR_43 $+1,208 \times$ VSHIR_41 $\left(\mathrm{R}^{2}=0,701 ; \overline{\mathrm{F}}_{(3,21)}=16,38 ; \mathrm{p}<0,001\right)$;

$D L \_S=16,01+2,154 \times$ VSHIR_11 + 2,735 $\times$ VSHIR_44 $-1,945 \times$ MDDEG_12 $-0,066 \times$ AU_AU $+0,259 \times$ MF_MF $+0,521 \times$ ALROOT_11 $-0,499 \times$ VLROOT_12 $-0,944 \times$ VSHIR_16 $\left(\mathrm{R}^{2}=0,937 ; \mathrm{F}_{(8.16}=29,88 ; \mathrm{p}<0,001\right)$;

GL_1 $=-8,194-1,674 \times$ VLROOT_12 $+0,427 \times$ ALROOT_13+0,116 $\times$ DUG_G_OP - 0,637 $\times$ L_43 - 0,198 $\times$ AU_GO $+0,735 \times$ ALROOT_11 - 0,271 $\times$ AL_AL $\left(\mathrm{R}^{2}=0,905 ; \mathrm{F}_{(7,17)}=23,14 ; \mathrm{p}<0,001\right)$;

GL_2 $=22,52+1,252 \times$ VLROOT_13 - 0,242 $\times$ EK_EK $+4,779 \times$ VSHIR_44 $-5,757 \times$ VSHIR_14 $+1,307 \times$ TSHIR_14 - 1,366 $\times$ VSHIR_12 $\left(\mathrm{R}^{2}=0,901 ; \mathrm{F}_{(6,18)}=27,12\right.$; $\mathrm{p}<0,001$ );

GL_3 $=-69,49+0,364 \times$ EU_EU $+2,722 \times$ TSHIR_43 $-0,148 \times$ EK_EK $-0,282 \times$ N_I $+0,113 \times$ DUG_G_OP $0,041 \times$ DUGS_G_OP $\left(\mathrm{R}^{2}=0,795 ; \mathrm{F}_{(6,18)}=11,60 ; \mathrm{p}<0,001\right)$.

\section{DISCUSSION}

The data obtained allow us to supplement the picture we obtained in previous studies and to make comparisons.

Of the 18 possible computed tomography sizes used to construct the correct dental arch shape, for young men with a wide face type constructed all 18 reliable models, depending on the characteristics of odontometric and cephalometric indicators with a coefficient of determination from 0.645 to 0.944 . In previous studies of Marchenko A.V. with colleagues [15, 16, 17] on a similar sample, it was found that the young men of the general group and mesocephals had 17 reliable models each 
(respectively $\mathrm{R}^{2}$ from 0.640 to 0.889 and 0.806 to 0.980 ), and in brachycephals - also all 18 models ( $\mathrm{R}^{2}$ from 0.894 to 0.965 ).

As a result of the analysis of our data, it is found that models built for young men with a wide face type more often include odontometric (69.7\%, of which $20.2 \%$ are on the upper incisors; $12.8 \%$ - on the lower incisors; $4.6 \%$ - upper canines; $11.0 \%$ lower canines; $10.1 \%$ - upper premolars; $7.3 \%$ - lower premolars; $3.7 \%$ - upper molars) than cephalometric (30.3\%) indicators. Among the odontometric indices, the most commonly models include: width of crowns of teeth in mesio-distal direction (22.9\%, of which $12.8 \%$ on upper jaw); the width of the crowns of the teeth in the vestibulo-oral direction (11.9\%, of which $9.2 \%$ on the upper jaw) and the distance from the middle of the cutting edge to the apex of the root of the teeth in the vestibulo-oral direction ( $11.9 \%$, of which $7.3 \%$ on the lower jaw). Cephalometric indicators most often include: the largest head circumference and nose height ( $2.8 \%$ each); sagittal arch, greatest width of head, exterior eye width, height of forehead, height of upper lip, depth of nose, distance from auricular point to chin and distance from auricular point to angle of lower jaw (1.8\% each).

In researches of Marchenko A.V. with colleagues $[15,16,17]$ found that the models built also more often include odontometric (in the general group - $71.3 \%$; in mesocephals $-56.3 \%$; in brachycephals - $74.5 \%$ ) than cephalometric indicators (respectively $28.7-43.7-25.5 \%$ ). The authors proved that in the general group and in brachycephals, the models most often include incisors sizes (30.4 and $41.8 \%$, respectively), and in mesocephals - incisors (20.6\%) and small angular teeth (21.8\%). In all groups, among the tooth sizes, the most frequently included tooth crown sizes were mesio-distal ( $25.4 \%$ overall; mesocephals $13.8 \%$; brachycephals $16.4 \%$ ) and vestibulo-oral (respectively $12.3-9.2-12.7 \%$ ) directions; width of the teeth at the level of the anatomical neck in the mesiodistal direction (respectively 9.0 -9.2-10.0\%); and only in mesocephals - the distance from the middle of the cutting edge to the apex of the root $(10.3 \%)$. Among the cephalometric indicators, the most frequently included models were: in the general group - the largest girth of the head (4.1\%), the external eye width, the transverse arc and the ear diameter $(2.5 \%$ each); for mesocephals, the average width of the face and the interoptical width (5.7\% each) and the distance between the nasion and the prosthion (3.4\%); in brachycephals - sagittal arch, height of upper lip, height of lower part of face and height of red border of lips ( $2.7 \%$ each).

However, it should be borne in mind that there are single works, the results of which indicate that there is no connection between the types of face and dental arch. Paranhos L.R. et al. [18] didn't investigate the association between the facial type and mandibular arch morphology among Brazilian Caucasians. The study included a sample comprised of 51 individuals (21 male and 30 female) with occlusion and without previous orthodontic treatment. The facial type was defined by SN.SGn and SN.GoGn. Statistical processing of the obtained results did not reveal statistically significant relationships.

In contrast, the vast majority of works in the analysis of literary sources point to the opposite. Anwar N. and Fida M. [19] compare dental arch dimensions and arch forms in various vertical facial patterns during the study of 100 persons of $13-30$ years ( 40 normodivergent, 30 hypodivergent and 30 hyperdivergent facial patterns). After statistical processing, it was discovered significant differences in arch dimensions in mandibular posterior intermolar width ( $\mathrm{p}=0.04)$ and maxillary total arch length $(\mathrm{p}=0.03)$.

Serbian researchers studied what types of faces are most commonly present in the population of Serbia and average values for the development of dental arches. Study performed on 300 subjects with class I dentoalveolar relations, for whom were determined the type of face and dental arches. The distribution of face types was: narrow $-50.33 \%$, medium type of face $-30.67 \%$, and wide $-19 \%$. The average anterior width of the lower dental arch was $35.93 \mathrm{~mm}$ and for upper was $36.75 \mathrm{~mm}$. And accordingly, posterior - 46.52 $\mathrm{mm}$ and $46.53 \mathrm{~mm}$. Average height of the upper dental arch was $24.22 \mathrm{~mm}$, and for the lower dental arch $19.32 \mathrm{~mm}$ [20].

Al-Taee H.M. and Al-Joubori S.K. [21] processed maxillary and mandibular occlusal frontal and lateral facial photographs of 90 ( 45 males and 45 females aged 18 - 25 years) Iraqi subjects to found the relationship between the shape of the dental arch and the types of face. Statistical data processing revealed significant differences in different groups of malocclusions and revealed manifestations of sexual dimorphism.

A similar study was conducted by a group of Indian scientists [22] on 90 untreated persons ( 45 males, 45 females in age 17-24 years) whom were measured the Jarabak ratio and performed different dental measurements. As a result, the relationship between cephalometric and dental arches was identified with manifestation of sexual dimorphism as in the previous study.

And as a result, Chinese scientists have conducted research to determine effects of transverse relationships between maxillary arch, mouth, and face on smile esthetics. They, after statistical processing of data, revealed indicators of the ratio of these objects with a probable error, which allow us to develop a kind of formula of a beautiful face [23].

Thus, the development of regression models, considering both craniometric and odontometric parameters, makes it easier for dentists. As can be seen from the literature, not only the anthropometric points but also the ethnic and regional characteristics play an important role in shaping the final outcome of treatment.

\section{CONCLUSIONS}

In adolescents with a wide type of face with normal occlusion, close to orthognathic occlusion, all 18 possible reliable (with a coefficient of determination from 0.645 to 0.944 ) regression models of reproduction of individual characteristics of dental arches of the upper and lower jaw depending on odontometric and cephalometric parameters were constructed.

\section{REFERENCES}

1. Gunas I., Glushak A., Samoylenko A. Dental arch Transversal characteristics in boys and girls with orthognathic bite: head shape and face type dependence. Current Issues in Pharmacy and Medical Sciences. 2015;28(1):42-45.

2. Marchenko A.V., Gunas I.V., Petrushanko T.0. et al. Computertomographic characteristics of root length incisors and canines of the upper and lower jaws in boys and girls with different craniotypes and physiological bite. Wiad. Lek. 2017;70(3 pt 1):499-502. 
3. Domenyuk D.A., Vedeshina E.G., Dmitrienko S.V. Correlation of dental arch major linear parameters and odontometric indices given physiological occlusion of permanent teeth in various face types. Archiv euromedica. 2016;6(2):18-22.

4. Bedoya A., Osorio J.C., Tamayo J.A. Dental Arch Size, Biting Force, Bizygomatic Width and Face Height in Three Colombian Ethnic Groups. International Journal of Morphology. 2015;33(1):55-61.

5. Anwar N., Fida M. Variability of arch forms in various vertical facial patterns. Journal of the College of Physicians and Surgeons Pakistan. 2010;20(9):565-570.

6. Othman S.A., Xinwei E.S., Lim S.Y. et al. Comparison of arch form between ethnic Malays and Malaysian Aborigines in Peninsular Malaysia. The Korean journal of orthodontics. 2012;42(1):47-54.

7. Traldi A., Valdrighi H.C., Souza L.Z. et al. Evaluation of facial morphology and sagittal relationship between dental arches in primary and mixed dentition. Dental press journal of orthodontics. 2015;20(4):63-67.

8. Grippaudo C., Oliva B., Greco A.L. et al. Relationship between vertical facial patterns and dental arch form in class II malocclusion. Progress in orthodontics. 2013 Dec 1;14(1):43.

9. Rai R. Correlation of nasal width to inter-canine distance in various arch forms. The Journal of Indian Prosthodontic Society. 2010;10(2):123-127.

10. Bushan M.G., Vasylenko Z.S., Hryhoreva L.P. Spravochnik po ortodontil [Orthodontics Guide]. Chisinau: Cartya Moldovenienasca; 1990. 486 p. (In Russian)

11. Gunas I.V., Dmitriev N.A., Marchenko A.V. Methodological aspects of computed tomography odontomorphometry of boys and girls with the physiological bite. Journal of Education, Health and Sport. 2015;5(11);345-355.

12. BunakV.V. Antropometriya. Prakticheskij kurs [Anthropometry. Practical course]. M.: Uchpedgiz; 1941. 367 p. (In Russian)

13. Profit R.W., Fields H.W., Sarver D.M. Sovremennaya ortodontiya [Modern orthodontics]. M.: MEDpress-inform; 2006.560 p. (In Russian)

14. Radchenko S.G. Metodologiya regressionnogo analiza [Regression Analysis Methodology]. Monograph. K. : «Korniychuk»; 2011. 375 p. (In Russian)

15. Marchenko A.V., Petrushanko T.0., Gunas I.V. Modeliuvannia za dopomohoiu rehresiinoho analizu transverzalnykh rozmiriv verkhnoi y nyzhnoi shchelepy ta sahitalnykh kharakterystyk zubnoi duhy v yunakiv v zalezhnosti vid osoblyvostei odontometrychnykh i kefalometrychnykh pokaznykiv [Modeling by regression analysis of the transversal dimensions of the maxilla and mandible and the sagittal characteristics of the dental arch in adolescents depending on the features of odontometric and cephalometric parameters]. Reports of morphology. 2017;23(1):107-111. (In Ukrainian)

16. Marchenko A.V., Gunas I.V., Petrushanko T.0. Rehresiini modeli indyvidualnykh liniinykh rozmiriv neobkhidnykh dlia pobudovy korektnoi formy zubnoi duhy v yunakiv mezotsefaliv v zalezhnosti vid osoblyvostei odontometrychnykh i kefalometrychnykh pokaznykiv [Regression models of individual linear dimensions required for constructing the correct dental arch shape in mesocephals youth, depending on the features of odontometric and cephalometric indicators]. World of medicine and biology. 2017;2(60):83-88. (In Ukrainian)

17. Marchenko A.V. Modeliuvannia transverzalnykh rozmiriv verkhnoi y nyzhnoi shchelepy ta sahitalnykh kharakterystyk zubnoi duhy v yunakivbrakhikefaliv v zalezhnosti vid osoblyvostei odontometrychnykh i kefalometrychnykh pokaznykiv [Modeling of transversal dimensions of the maxilla and mandible and sagittal characteristics of dental arch in young brachycephals depending on the features of odontometric and cephalometric parameters]. Bulletin of the Vinnitsa National Medical University. 2017;21(2):396-400. (In Ukrainian)

18. Paranhos L.R., Ramos A.L., de Novaes Benedicto E. et al. Is there any association between facial type and mandibular dental arch form in subjects with normal occlusion? Acta Scientiarum. Health Sciences. 2014;36(1):129-134.

19. Anwar N., Fida M. Clinical applicability of variations in arch dimensions and arch forms among various vertical facial patterns. Journal of the College of Physicians and Surgeons Pakistan. 2011;21(11):685-690.

20. Arbutina A., Cupić S., Umićević-Davidović M. et al. Face types and sizes of dental arches in subjects with class I molar relationship. Glasnik Antropološkog društva Srbije. 2012(47):41-50.

21. Al-Taee H.M., Al-Joubori S.K. Dental arches dimensions, forms and its association to facial types in a sample of Iraqi adults with skeletal and dental class II-division 1 and class III malocclusion (A cross sectional study). Journal of Baghdad College of Dentistry. 2014;26(2):160-166.

22. Khera A.K., Singh G.K., Sharma V.P. et al. Relationship between dental arch dimensions and vertical facial morphology in class I subjects. Journal of Indian Orthodontic Society. 2012;46(4_2):316-324.

23. Zhang K., Huang L., Yang L. et al. Effects of transverse relationships between maxillary arch, mouth, and face on smile esthetics. The Angle Orthodontist. 2016;86(1):135-141.

Research on the normative indicators of health of the population of Ukraine are included in the Concept of the National Program «Health 2020: The Ukrainian dimension» (Ordinance of the Cabinet of Ministers of Ukraine of 31.10.2011 №1164-p). The work is a fragment of scientific topics National Pirogov Memorial Medical University, Vinnytsia "Current trends and newest technologies in the diagnosis and treatment of odontopathology, diseases of periodontal tissues and mucous membrane of the mouth» (State registration number: 0119U005471).

\section{ORCID and contributorship:}

Alla V. Marchenko - 0000-0003-2178-6383 B,F

Mariya M. Shinkaruk-Dykovytska - 0000-0002-0747-4247 ${ }^{A, F}$

Taras P. Pozur - 0000-0001-6611-018X ${ }^{B, C, D}$

Valery I. Gunas - 0000-0002-0778-7737 ${ }^{\mathrm{B}}$

Volodymyr O. Orlovskiy - 0000-0001-5569-6576 ${ }^{E}$

\section{Conflict of interest:}

The Authors declare no conflict of interest.

\section{CORRESPONDING AUTHOR Alla V. Marchenko \\ Ukrainian Medical Stomatologikal Academy \\ Shevchenko street 23, 36011 Poltava, Ukraine \\ tel: +380506059436 \\ e-mail:allamarchen@ukr.net}

Received: 22.02 .2020

Accepted: 30.04 .2020 